\title{
ALFONSO X EL SABIO Y EL SÍMBOLO DEL LEÓN: LA RELEVANCIA DEL LEÓN DENTRO DE LA GENERAL ESTORIA
}

\author{
ALFONSO X EL SABIO AND THE LION SYMBOL: \\ THE RELEVANCE OF THE LION WITHIN \\ THE GENERAL ESTORIA
}

\section{Adriana GALLARDO LUQUE}

Universidad Complutense de Madrid adriagal@ucm.es

Resumen: El presente artículo se centra de forma exclusiva en la figura del león, animal de alto valor simbólico desde la antigüedad. En este trabajo se pretende incidir en la fuerza y en el significado de este animal dentro del universo de Alfonso X el Sabio, y en concreto, dentro de su General Estoria, obra en la que como veremos el animal toma un papel sobresaliente.

Palabras clave: Alfonso X el Sabio. León. General Estoria. Heráldica.

Abstract: This article focuses exclusively on the figure of the lion, animal form with a high symbolic value since ancient times. This work aims to have an impact on the strength and meaning of this animal within the world of Alfonso X el Sabio, and in particular within his General Estoria. As we will see, in this work the animal takes an outstanding role because it boosts the importance of this king. 
Key Words: Alfonso X el Sabio. Lion. General Estoria. Heraldry.

\section{INTRODUCCIÓN}

\subsection{EI león en el imaginario cristiano}

La imagen del león en la Edad Media es excesivamente densa, ya que puede ser vista en multitud de soportes y de contextos, además de tener pluralidad en su lectura, hallándose el león en una gran afluencia de fuentes. M. Pastoureau (Pastoureau, 1984: 135) ya apuntó en 1985 que el león es mencionado en el texto bíblico unas 157 veces, siendo ésta la fuente principal para su simbología durante la primera Edad Media cristiana.

En la materia bíblica lo encontramos en primer lugar relacionado con las fuerzas del mal, siendo retratado como un animal extremadamente peligroso, viéndose ésta misma imagen de forma clara en los Salmosi: "Señor, Dios mío, tú eres mi refugio, sálvame de mis perseguidores, sálvame; no sea que, como leones, me desgarren, me despedacen sin que nadie me libre" (Sal. 7, 2-3). "[...] con sus ojos espía al desdichado; escondido como un león en su guarida, al acecho para atrapar al miserable, lo atrapa enredándolo en sus redes; se agazapa y se encoge, el desvalido cae en sus garras" (Sal. 10:9-10). "[...] Toros innumerables me acorralan, me acosan los toros de Basán; ávidos abren contra mí sus fauces, cual leones que rugen y desgarran" (Sal. 22:13-14). "[...] sálvame de las fauces del león, mi pobre vida de los cuernos del búfalo [...]” (Sal. 22:22). “[...] Vivo en medio de leones que devoran hombres, sus dientes son lanzas y flechas; su lengua, una espada acerada [...]" (Sal. 57[56]: 5:). "[...] andarás sobre el león y la serpiente, pisarás al tigre y al dragón [...]" (Sal. 91 [90]: 13).

Por otro lado la Biblia también aportó una lectura cristológica de esta bestia al hablarnos por ejemplo del León vencido por Sansón ${ }^{2}$, siendo

1. Para todas las citas bíblicas se ha utilizado la versión de La San Biblia, editorial San Pablo de

2. “Bajaba Sansón a Timná, y, al llegar a las viñas de Timná, le salió al encuentro un cachorro de león rugiendo. El espíritu del Señor se apoderó de Sansón y, con sólo las manos, desgarró al león como se desgarra un cabrito. Pero no contó a sus padres lo que había hecho". (Jueces. 14:5-6). 
aquí la muerte del león una imagen profética de la muerte de Jesucristo y Sansón, la imagen de la humanidad (Charbonneau-Lassay, 1997: 39-40), o el León de Judá: "Cachorro de león es Judá, de hacer presa subes, hijo mío. Se encorva, se echa como un león, como leones; ¿quién podrá levantarlo?" (Gn 49:9) ${ }^{3}$, y por supuesto, no debemos olvidar la identificación que se realiza con san Marcos evangelista y este animal en la iconografía del tetramorfos. En esta misma línea, san Ambrosio y Orígenes lo trataron como prefiguración de Cristo.

Fueron el Fisiólogo griego y san Isidoro de Sevilla quienes dentro del pensamiento cristiano atribuyeron al león grandes atributos: la fuerza, el poder y el amor. Fue de la sabiduría de ambos autores de la que fundamentalmente se sirvieron los bestiarios de la plenitud medieval y de estos manuscritos conocidos como bestiarios bebió la imaginación de muchos heraldistas (Valero de Bernabé, 2007: 126), los cuales convirtieron al león en un símbolo perfecto del cual muchos linajes quisieron apropiarse pero del que los reyes de León eran herederos legítimos tras la aceptación de la inscripción Legio VII como León (Menéndez-Pidal de Navascués, 1999: 23-33), además de servirse tal y como expone el profesor Nogales Rincón de la asociación de leo fortis/rex fortis (Nogales Rincón, 2011: $85)$.

\subsection{EI Bestiario heráldico en la Edad Media}

Para hablar del león que aparece retratado dentro de las páginas de la General Estoria, caso particular que aquí nos ocupa, es del todo necesario detenernos en el estudio del conocido como "Bestiario heráldico". Este interés o especialidad dentro del estudio de la materia heráldica medieval se encarga, como su propio nombre indica, de investigar las figuras zoomórficas que aparecen reflejadas en los blasones, siendo ésta fundamental para el estudio de la heráldica europea debido a que -como es bien conocido-, la figura humana no fue aceptada dentro de la mentalidad cristiana europea, motivo por el que el animal pasó a ser protagonista dentro de la simbología del blasón. Uno de los más populares fue el león, considerado como uno de los "reyes del bestiario heráldico" (Valero de Bernabé, 2007: 128), motivo por el cual lo reyes de León se valieron de la

3. Véase también: Sam.1, 23; 2; Mac. 11, 11; Prov. 30, 30. 
imagen de su animal desde sus primeros tiempos.

El interés por la faceta heráldica del animal no es reciente. El estudio de éste despertó con fuerza en la década de los ochenta del pasado siglo, donde destacó la tesis del conocido semiótico francés M. Pastoreau (1972), realizando el profesor Pastoureau posteriores trabajos en torno al mundo de la heráldica y también otros que se han centrado en el protagonismo que el animal tuvo en la mentalidad medieval. Desde la esfera anglosajona, destacan trabajos como los de Peter Gwynn-Jones (1993), Heraldic Monster. Y en cuanto a España, sobresalen estudios como los del experto en heráldica y genealogía José María de Montells (1999) y su obra titulada Diccionario Heráldico de Figuras Quiméricas y otros términos relacionados con la Ciencia del Blasón, publicado $1999^{4}$.

\section{ALFONSO X EL SABIO Y SU RELACIÓN CON EL SÍMBOLO DEL LEÓN}

Unas simples pinceladas biográficas servirán para introducir a un rey tan notorio. El rey Alfonso, el apelado como el Sabio, nació el 23 de noviembre de 1221 en la ciudad de Toledo, muriendo a la edad de 62 años, el 4 abril de 1284, en la ciudad de Sevilla. Fue éste el legítimo heredero de su padre, Fernando III, el cual había conseguido heredar las coronas de Castilla y de León, además de ser el ganador de una gran cantidad de territorios pertenecientes al poder musulmán de la península. Su madre, Beatriz de Suabia, era descendiente de los emperadores alemanes, motivo por el cual Alfonso el Sabio intentó ser coronado emperador del Sacro Imperio Romano Germánico. Ha sido mucho lo que se ha escrito y especulado sobre la obsesión del rey por llegar a obtener el título de emperador alemán, no obstante aquí nos interesa la otra cara de la moneda, la ambición de éste por llevar el título de emperador de su bisabuelo Alfonso VII.

En pleno siglo XIII, el intelectual catalán Ramón Muntaner ${ }^{5}$,

4. En el terreno ibérico no podemos olvidar los trabajos imprescindibles del profesor Ignacio Malaxecheverría (2008: 90-94), donde muestra una descripción del león según en bestiario en lengua romance. Además se debe de tener en cuenta la traducción del Fisiólogo al castellano de N. Gugliem (2002), El Fisiólogo. Bestiario medieval.

5. Ramón Muntaner (1269-1336) fue un caballero y escritor de la Corona de Aragón, el cual escribió la conocida como la Crónica de Muntaner, que comprende desde la concepción de Jaime I (1207) hasta la coronación de Alfonso IV de Aragón (1328). 
personaje que tuvo el honor de conocer en persona a este rey, escribió que lo que de verdad le interesaba a Alfonso X de León y IX de Castilla no era el Imperio Alemán, sino ser emperador de España "esser emperador d'Espanya" (González Jiménez, 2004: 11). Es decir, convertir su doble corona $^{6}$, tanto la de León como la de Castilla, en un reino único y superior, sobresaliente ante los demás reinos peninsulares. Como vemos, el rey Sabio mostró desde el principio un objetivo muy claro respecto a este asunto, conseguir la restauración por vía de facto del viejo Imperio Hispánico siguiendo el modelo de su venerado ancestro, Alfonso VII el Emperador. De tal modo que Alfonso se sintió capacitado para llevar la corona del imperio hispánico, sueño que había contemplado su padre, Fernando III, ya que éste último al coronarse y consolidarse como rey de León no dudó en reivindicar para sí el título de emperador (González Jiménez, 2004:74) 7 .

Tal y como expresa el profesor Carlos de Ayala:

[...] El gran objetivo del rey, incluso en los días de una mayor propagand imperial ${ }^{8}$, no estaba fuera de la península sino en su interior, porque de lo que se trataba era de consolidar un poder fuerte en el seno del propio reino y asegurar una indiscutible hegemonía política en el conjunto de los otros reinos hispánicos [...] (Ayala, 20042005: 102).

\subsection{El símbolo del león heredado por el rey Sabio}

Ya advirtió en su día Faustino Menéndez (1982: 23) del uso temprano

6. El profesor Cayetano J. Socarrás no dudó en afirmar que desde sus primeros días de gobierno Alfonso el Sabio tuvo muy claro cuáles iban a ser sus principales metas políticas, por eso en 1252, al poco tiempo de heredar la corona de su padre, el rey Sabio y el rey Alfonso III de Portugal firmaron un tratado de amistad. En este tratado se expresaba con claridad dos cosas: primero, el deseo de convertir la zona del Guadiana en la frontera física, desde el Caya hasta el mar, entre Portugal y León; y, en un segundo punto, el reconocimiento por parte de Alfonso III de la soberanía de Alfonso el Sabio sobre el Algarbe, pero insertándola, no dentro de la causa ideología del imperium leonés, sino de un Imperium Hispanicum que fuese, como propone Socarrás, "expresión de la preeminencia del rey castellano sobre los restantes reyes de la Península Ibérica" (Socarrás, 1976).

7. En 1234 Fernando III trató de conseguir el título de emperador ante la curia romana, pero fue denegado por el papa Gregorio IX, éste enemistado con el emperador Federico II no estaba interesado en otro monarca titulado como emperador.

8. Sobre el concepto de "propaganda" en tiempo de Alfonso X, véase Kleine (2013: 4). 
que hizo Alfonso VII del león en sus armas y banderas, aportando unos párrafos que nos ofrece la Crónica latina:

Florida milities post hos urbis Legionis

Portans vexilla, prorumpit more Leonis.

Haec tenet Hispani totius culmina Regni,

Regali cura scrutatur Regia jura,

Ejus juicio patriae Leges moderantur,

Illius auxilio fortissima bella parantur.

Ut Leo devincit animalia, utque decore,

Sic cunctas urbes hoc vincit prorsus honore,

Lex fuit antiqua, sunt ejus praelia prima,

Sunt in vexillis, et in armis Imperatoris,

Illius signa tutania cuncta maligna,

Auro sternuntur quoties ad bella geruntur,

Coetus Maurorum visu prosternitur horum

Nec valet in parvo consitere territus arvo

(Chronica Adelfonsi Imperatoris, vv. 66-79).

A pesar de estas líneas este rey no llegó a servirse lo suficiente de su símbolo zoomórfico. Véase el caso de los sellos de Alfonso VII, los cuales son de tipo mayestático y carecen de cualquier manifestación heráldica, usando este rey los signos de la cruz enarbolada, considerados como un emblema preheráldico de amplia extensión en todos los reinos españoles. No obstante, algunas monedas de Alfonso VII sí nos ofrecen las representaciones más antiguas del león. En estas monedas el león aparece pasante, generalmente a la derecha y ocupando todo el campo de una de las caras de la moneda. En algunos ejemplares el león parece tener cabeza humana, siendo una curiosa variante que debió de ser usada en la heráldica. Desdichadamente, a pesar del fragmento de la Crónica Latina, estas monedas son las únicas representaciones heráldicas ciertas del león en el reinado del emperador (Menéndez, 1982: 24).

Por parte de su heredero a la corona de León, Fernando II de León, tenemos una representación muy especial de un león heráldico ${ }^{9}$ dentro

9. Esta imagen puede verse en el folio $44 \mathrm{v}$ del manuscrito, en éste, en la parte superior de la página se encuentra representado al rey de León, armado y cabalgando, mientras que en la parte interior del folio aparece un león en posición vertical, rampante, contorneado a la siniestra, con la mirada en la misma dirección en la que 
del Tumbo $A$ de Santiago de Compostela ${ }^{10}$, siendo una demostración gráfica de la importancia del uso del signo del león ${ }^{11}$. Según Faustino Menéndez Pidal todo parece indicar que en los tiempos de Fernando II tuvo lugar la formalización de las armas de León, partiendo éstas de su símbolo zoológico y parlante (Menéndez Pidal de Navascués, 1982: 42), cuya existencia es ya segura en el reinado de Alfonso IX. De tal modo que con Fernando II las monedas llevarán siempre el león como señal, desplazando completamente a la antigua cruz enarbolada ${ }^{12}$.

El siguiente rey en esta línea sucesoria fue Alfonso IX, el cual usó del mismo modo que su predecesor el león en sus armas, utilizando a menudo para su documentación el símbolo del felino. En la representación del Tumbo $A$ de la Catedral de Santiago (miniatura que se estima que pudo ser creada en torno a 1208), aparece el rey en la parte superior del folio retratado sobre fondo de oro, y en la parte inferior de la imagen, enmarcado por una franja verde, queda encerrado el símbolo del rey, un león teñido en tonos purpuras ${ }^{13}$ que fue pintado sobre pergamino y sin coloración en su fondo.

Fue en tiempos del reinado del padre del rey Sabio, Fernando III, el conocido como el Santo, rey de Castilla desde 1217 y rey de León desde 1230, cuando se unen definitivamente las coronas de Castilla y de León, aportando este rey una innovación heráldica que aún nos acompaña, el cuartelado de los reinos de Castilla y de León ${ }^{14}$. La intención del cuartelado

marcha el rey caballero, éste aparece sin color, de ahí que se le haya denominado como "león protoheráldico", y junto a él la inscripción "LEO FORTIS” (Menéndez Pidal de Navascués, 1982: 39).

10. En este artículo nos interesan los retratos de los reyes incluidos en el conocido como Tumbo $A$ de la Catedral de Santiago de Compostela. Éste es un compendio de información que va mucho más lejos del mero dato iconográfico. El Tumbo A de la Catedral de Santiago de Compostela comenzó su formación gracias a la insistencia del prelado Diego Gelmírez, recogiéndose en éste la documentación real relacionada con la Catedral de Compostela. Los primeros 40 folios del Tumbo son los que corresponden a la producción inicial, realizada entre 1129 y 1134 en ocho cuaterniones. Los siguientes 31 folios responden a cerca de cuatro adiciones posteriores (con un quinión y varios bifolios) entre los siglos XII-XIII, finalizando en 1255, correspondiendo los folios utilizados en este artículo a la segunda fase del códice.

11. Los retratos de monarcas comienzan en el Tumbo A con la representación de Alfonso II y concluyen con la de Alfonso X el Sabio, encontrándose cada una de las figuras en el encabezado para el desarrollo de la documentación del rey en cuestión.

12. Los leones de las monedas y los sellos fueron retratados con la cintura muy estrecha y los cuartos anteriores grandes, la cabeza pequeña y con la mano derecha levantada, respondiendo la figura al denominado como león románico, (Menéndez Pidal de Navascués, 1982: 43).

13. El león heráldico original es de color púrpura tal y como demostró a finales del siglo XIX Jean Van Malderghem en su libro publicado en 1898: Du purpre en héraldique.

14. Desde 1231 hay sellos de san Fernando en los que lleva el escudo en las coberturas del caballo y, en el reverso del sello, dos castillos y dos leones, dispuestos como en el cuartelado, aunque no sobre un escudo, sino en el campo circular (Menéndez Pidal de Navascués, 1982: 88). 
era la de demostrar la fusión de las armas de ambos reinos formando un todo indivisible y no en yuxtaposición transitoria, quedando ambas armas en igualdad de rango (Menéndez Pidal de Navascués, 1982: 88).

Alfonso el Sabio fue consciente de la evolución que su símbolo zoológico, el león, había sufrido con sus predecesores y no dudó en hacer uso del poder y la simbología que éste contenía. A través de las fuentes escritas e iconográficas que nos han llegado de este rey podemos ver el buen uso que éste hizo de sus símbolos heráldicos, llegando incluso hasta hacer gala de los mismos en sus propias vestiduras. Pero independientemente de la representación y la promoción puramente estética de este símbolo, Alfonso X supo reiterar la importancia del león a través de diferentes obras, siendo una la que aquí nos ocupa, la General Estoria.

\section{GENERAL ESTORIA}

\subsection{Historiografía actual}

Fue el ayudante de Ramón Menéndez Pidal, el filólogo y medievalista español Antonio García Solalinde, quien en la tercera década del siglo XX entendió el obligatorio y necesario estudio de la obra completa de la General Estoria. Por desgracia el trabajo de éste no pudo concluirse en su tiempo, hecho bastante comprensible si pensamos en la pésima situación de nuestro país en la mitad de los años treinta, pero no obstante sí nos dejó una primera edición crítica de la Primera parte de la General Estoria (Alfonso X El Sabio, 1930).

En la actualidad toda la obra ha sido editada bajo la dirección de Pedro Sánchez-Prieto (en Alfonso X, 2009), encontrándose ésta en diez tomos, cada uno de los cuales ha sido correctamente editado por diferentes especialistas.

\subsection{La obra}

La General Estoria puede entenderse como una extensa compilación de historia universal de carácter enciclopédico redactada probablemente en los últimos quince años del reinado de Alfonso X (Primera parte, 2 vols., 2009: XLV.). En opinión de Pedro Sánchez-Prieto, la hipótesis más acertada para acercarse a la motivación que pudo tener Alfonso X 
para redactar una obra tan complicada no pudo ser otra que "la extrema curiosidad del rey y sus colaboradores" (Alfonso X, Primera parte, 2 vols., 2009: XLV).

En el momento de su creación no había una obra que alcanzase las medidas de la General Estoria, siendo lo más parecido el compendio apelado como la Historia Scholastica de Pedro Coméstor ${ }^{15}$. Por otro lado, mientras que la General Estoria goza de ser una obra exhaustiva y enciclopédica, la Estoria de España pretende seguir unas "estrictas" metodologías históricas. Nuestra obra protagonista muestra tanto versiones textuales de la Biblia romanceada, como de la Biblia latina, ya que, como se demuestra con la lectura de la obra, los escritores de la misma pretendieron compilar noticias y conocimientos de todo orden. La complejidad de la obra ha hecho que los investigadores encargados de su estudio lleguen a la conclusión de que si hay que catalogar a esta obra en algún género, "debe de ser el que se inicia y se termina con esta misma obra" (Alfonso X, Primera parte, 2 vols, 2009: XLVIII).

La General Estoria ha sobrevivido en seis partes, aunque es bastante factible que la primera intención del rey Sabio fuese la de alcanzar el número de siete volúmenes, no correspondiendo estas seis partes con las Edades del Mundo en las que se solía dividir el tiempo en el siglo XIII. Las tres primeras edades ocupan la parte Primera, la cual supone pues la traducción íntegra del Pentateuco ${ }^{16}$, y la parte Segunda de la General Estoria, abarca los años de la muerte de Moisés hasta la muerte de David e incluye un número mayor de episodios sobre los gentiles que las otras partes. Corresponde en la Biblia a los libros de Josué, Jueces, Ruth, al primer libro de los Reyes y segundo de los Reyes, segundo de Samuel, reinado de Saúl y posteriormente de David y dos capítulos del tercero de los Reyes, mientras que la Tercera se dedica a la cuarta edad, que va desde el reinado de David a la "trasmigración" de Babilonia, que se cuenta en la Cuarta parte. La Quinta parte abarca la segunda mitad de la quinta edad, es decir desde el año 209 a. C. hasta pocos años antes del nacimiento de Cristo. La obra finaliza con la Sexta parte, que comienza hablando de los

15. En la obra de Pedro Coméstor existe una proporción muy alta de historia bíblica y en cambio en la General Estoria existe una equilibrada proporción entre historia bíblica e historia de los gentiles (Alfonso X, Primera parte, 2 vols, 2009: XLV).

16. El modelo estructural de esta primera parte fue, como en el conjunto de la General Estoria, los Cánones Crónicos de Eusebio de Cesárea (siglo IV), continuados por san Jerónimo (siglos IV-V). 
padres de Juan Bautista y de la Virgen, interrumpiéndose bruscamente en la concepción de la Virgen por Santa Ana (Salvo García, 2010).

\subsection{Fuentes}

Como ya hemos expresado, la base de la que emana la obra es la materia bíblica, sin embargo a lo largo de las páginas de esta monumental obra enciclopédica son muchas las fuentes de las que fueron bebiendo los compiladores de la misma. En la Primera parte observamos cómo se utilizan los Cánones Crónicos de Eusebio de Cesárea (siglo IV) continuados por san Jerónimo (siglo IV-V) ${ }^{17}$. Es muy importante localizar las fuentes profanas y religiosas que utiliza, ya que desde la primera parte de la obra vemos el uso de autores como Ovidio (Salvo García, 2012) ${ }^{18}$, Plinio el Viejo y Estrabón, los cuales fueron utilizados para las diferentes partes del mundo y en nuestro interés particular para las diversas animalidades que se encuentran en aquellos lugares, entrando en este campo como fuente fundamental la Historia Natural de Plinio el Viejo ${ }^{19}$. Pero al mismo tiempo que utiliza a este último, hace también uso del conocimiento de las mencionadas Etimologías de san Isidoro de Sevilla (García Solalinde, 1934) ${ }^{20}$ y también menciona directamente, como ya destacó García Solalinde en la década de los treinta, el manejo de una versión del Fisiólogo (García Solalinde, 1930) y otra posible fuente que ya mencionó Tomás González pudo ser De Universo, de Rábano Mauro (González Rolán, 1981).

17. Estos cánones fechan los hechos ocurridos a lo largo de la historia del mundo desde su creación hasta el momento contemporáneo a su composición.

18. La General Estoria hace uso de la Metamorfosis de Ovidio sobre todo en las anotaciones históricas del poema, ya que éste narra de manera versificada la historia de la Creación del mundo hasta la deificación de Julio César, gustando GE del uso de muchos mitos que en esta obra se encuentran. Esta obra fue muy utilizada por los escritores medievales y sobre todo por los poetas, de ahí que no sea nada extraño el uso de esta obra en la composición de GE. El tema de Ovidio en la GE se ha encargado de estudiarlo la profesora y filóloga de la UAM Irene Salvo García (2010).

19. La Historia Natural fue dividida en 37 libros y pretendía albergar todo lo que Plinio entendía como sabiduría natural, de ahí que podamos encontrar conocimientos de zoología, de botánica, de antropología, de geografía y muchos más. Es bastante notable el uso del libro III: Geografía del Mediterráneo occidental; libro IV: Geografía del Mediterráneo oriental; el uso del libro V: Geografía de África, Oriente Medio y Turquía; libro VI: Geografia de Asia; libro VII: Zoología de los animales terrestres. Siendo este libro el que nos interesa a nosotros para nuestro desarrollo, además de estos libros mencionados también fueron utilizadas otras partes de la Historia Natural.

20. En este artículo el medievalista García Solalinde afirma el uso de la fuente árabe Los caminos y los reinos (Kitab al-masalik wal-mamalik), obra que en ocasiones parece enfrentarse con la sabiduría del libro XIV de las Etimologías de san Isidoro. 


\subsection{La animalidad en General Estoria}

Como ya hemos señalado, esta obra contaba con la gran ambición de poder albergar "toda la Historia del mundo", incluyéndose también todos los conocimientos que a lo largo de la historia el hombre había alcanzado. De ahí que dentro de esta obra encontremos, por un lado, sabiduría animal puramente enciclopédica, basada en tratados como los de Plinio el Viejo, Estrabón etc; un ejemplo podría ser la descripción del Buey de Apis que se toma de la Historia Natural de Plinio (Alfonso X, Primera parte, vol.2, 2009: 18-19) $)^{21}$, viéndose en este fragmento tanto la necesidad de curiosidad, como el ansia de conocimiento y de añadir erudiciones a la materia bíblica por medio de todos los recursos que los compiladores tenían a su alcance. Pero al mismo tiempo, tenemos que tener en cuenta la aparición del abundante número de animales que aparecen en las Sagradas Escrituras, encontrándose éstos en muchos casos mencionados de la misma manera y con el mismo valor simbólico con el que pueden aparecer en las Biblias romanceadas del momento, siendo un ejemplo claro la gran cantidad de animales que aparecen mencionados como ofrenda para el sacrificio a lo largo de toda la versión del Antiguo Testamento desarrollada en la General Estoria.

\section{EL LEÓN EN LA GENERAL ESTORIA}

Dicho todo esto, ¿qué importancia es la que tiene la abundante puesta en escena del león en la General Estoria? En primer lugar debemos de tener en cuenta la cuantiosa aparición del león en los textos bíblicos, ya que la General Estoria los toma como fuente primordial. Pero también adquiere los conocimientos zoológicos de otros autores, quedando latente a pesar de todo que la intromisión del león en la obra va mucho más $\operatorname{lejos}^{22}$. Es perceptible que existe una intencionalidad, viéndose en el uso

21. Libro XI, Capítulo IX. Del Buey Apis de Egipto. y Capítulo X: De como fazién los egipcipcianos del nuevo Apis: Cuenta luego Plinio d'él e dize assí, que avié en Egipto un toro que llamavan los egipcianos el buey de Apis, e aorávanle por dios, e cuenta su fechura e sus fechos, e cómo fazién con él los d'essa tierra. E dize que avié este toro en el diestro costado una señal muy noble, e era una mancha blanca fecha a manera de los cuernos de la luna cuando sale nueva, e los cuernos otros tales, e diz que avié un nudo en la garganta de la lengua contra Ayuso a que llamavan los egipcianos cantaro.

22. Hemos encontrado a lo largo de la General Estoria el vocablo "leon" en 43 casos, no descartando la existencia de este en más casos. 
del león un símbolo "propagandístico" con el cual se pretende ensalzar algunas de las virtudes del monarca. Para esto los compiladores de la obra no dudaron de servirse de todo tipo de fuentes, tomando en muchos casos tan solo las definiciones que eran interesantes para tal fin.

Si observamos algunos fragmentos de la obra podemos encontrar esta intencionalidad. En los textos 1 y 2 leemos sobre la naturaleza piadosa del león, encontrándonos la descripción de un monarca gentil con sus súbditos, el cual es capaz de perdonar las pasadas ofensas tras un acto de rendición como es el de la humillación y sometimiento por medio de la genuflexión del vasallo - o inferior - ante su señor. Capítulo X: De las naturas del león de la braveza e la su mansedumbre:

[...] E el león á por natura de ser piadoso al qui se lo omilla, $e$ all omne que se echa ant él en tierra non fazen ningún mal. E que cuando mal quiere fazer quel faze más aína a los varones que a las mugieres, e a los moós nuncua va si non con grand arrequexamiento e fambre [...] (Alfonso X el Sabio, Primera parte, 2009: 551-552) ${ }^{23}$. Texto 1

Capítulo X: De las naturas del león de la braveza e la su mansedumbre:

[...] Creen los omnes de Libia, segund cuenta Plinio en esse capitulo, que los leones entienden ruegos, ca diz que oyó él que una cautiva fuera de tierra de Betulia e viniera a unas selvas en que falló un león muy cruel de luego, $e$ començól ella a decir mucho omidosamientre cómo ella era cativa e emferma e flaca cosa, e assíl rogando quel amansó por su ruego, e dexóla [...] (Alfonso X el Sabio, Primera parte, 2009: 551-552).

Texto 2

Otra característica muy importante que puede pasar desapercibida es la longevidad del león con respecto a otros animales. En el texto 3

23. Tomando como fuente principal la Historia Natural de Plinio el Viejo (2003: 138-139). 
se nos cuenta como muchos de éstos llegan a tener tantos años que se quedan sin dientes y que es en este caso cuando terminan por atacar a los humanos, ya que no pueden servirse de las raudas bestias salvajes. En este distintivo podemos ver tanto la sabiduría que alcanzan los mayores como la eternidad que puede llegar a alcanzar un rey, es decir, la supervivencia del león está relacionada con la eternidad de los propios reyes. Capítulo X: De las naturas del león de la braveza e la su mansedumbre:

[...] E viven mucho los leones, e diz que esto se prueba porque fallan los omnes muchos d 'ellos sin dientes. Un sabio que llamaron Polibio dize que los leones viejos comen a los omnes porque non pueden ya por su correr alcançar las bestias, e por esto fallamos en las estorias que los leones que muchas vezes cercaron cibdades en África pora tomar ý algunos omnes que comiessen [...] (Alfonso X el Sabio, Primera Parte, 2009: 551-552) ${ }^{24}$.

Texto 3

En el texto que tenemos a continuación aparecen diferentes muestras de las peculiaridades del animal, desde el buen corazón que posee al no atacar a los cazadores que vienen hacía él, como la gran astucia que tiene el león al esconderse de estos cazadores, no llegando a ser encontrado ni siquiera por los perros que con los hombres lo buscan. Otra anotación bastante destacable es en la que se apunta el último momento de vida del león, al morder la tierra y romper a llorar se refleja el compromiso y el amor que el buen rey tiene por su tierra y la enorme pena que éste carga al dejar huérfanos a sus súbditos ${ }^{25}$. Capítulo XI, De la nobleza, dell esfuerço del león e de la fuerça:

[...] La nobleza del coraçon del león parece mayormientetre en los periglos, ca a las vegadas vienen los caçadores e fallan el león e échanle muchos dardos e azconas,

24. Tomando de nuevo como fuente principal la Historia Natural de Plinio el Viejo (2003: 138).

25. Este comportamiento que el león tiene a la hora de morir nos recuerda al que se describe en la Segunda Partida, título 11, Ley 1 del compendio jurídico que mandó hacer el rey Sabio, las Siete Partidas: [...] Tenido es el rey, no tan solamente de amar, e honrar, e guardar a su pueblo así como dice en el título ante de éste, más aún a la tierra misma de la cual es señor, pues que él e su gente viven de las cosas que en ella son [...] (Alfonso X el Sabio, 2004: 230). 
e él non se quiere mover. E assí como cuenta Plinio en aquel capítulo ${ }^{26}$, esto non faze él por miedo, mas por muy grand ira quel toma; e cuando vee grand fuerça de canes caçadores si es en logar estrecho vasse él a logar ancho e espacioso, e cuando se va pora aquel logar si passa entre matas o árvoles corre muy fuert, e cuando passa por logar escampado va de vagar; e esta priessa de andar faze él entre las maas e los árvoles porque non tengan que se asconde, ca tien que asconderse es grand vileza. E cuando él seguda faze grandes saltos, e non los quiere fazer cuandol segundan. Al quil fiere coñocel e paral mientes, e entre todos a aquél va matar; e cuando alguno le echa alguna arma e nol fiere va a él e echal en tierra e rebuelvel entre los pies, mas nol quiere matar nin llagar. E cuando acaece que la leona á de lidiar por sos fijos quel quieren levar finca lo ojos en tierra que non se espante de las armas nin dé nada por ellas. Otra guisa los leones non son engañosos nin sabiodores de nemiga como otras animalias á $y$, nin sospechosos, e catan omillosamientre, $e$ assí quieren que los caten los omnes. E dizen los sabidores de la natura d'ellos que cuando muere el león que muerde la tierra e llora, e grand maravilla es d'esta su natura que tan fuert bestia como ésta es de grand coraçón que se espanta cuando vee redes o gallos, e mayormientre cuando los gallos oe cantar. Teme mucho el fuego. Non siente otra enfermedat ninguna si non de fastio, e d'éste se enoya tanto que semeja que ravia, e enójase mucho cuando vee trebejar los simios, e sana d ello cuando beve sangre. [...] (Alfonso X el Sabio, Primera parte, 2009: 552-553).

Texto 4

La última descripción que traemos aquí es muy importante, ya que se encontraba íntimamente relacionada con la estética que tomó el león dentro de la imaginación heráldica del momento. Capítulo X: De las naturas del león de la braveza e la su mansedumbre:

26. Tomando como fuente principal la Historia Natural de Plinio el Viejo (2003: 140). 
[...] La cola demuestra el coraçón del léon como las orejas el coraçón del cavallo, e cuando non quiere fazer mal tien la cola queda, e cuando lo quiere fazer fiere primero en la tierra con la cola e desend a sí mismo en ell espinazo. La mayor fuerça del león es en los pechos. De toda llaga que él faga sale la sangre negra, e esto de sunatura es d'él. Cuando son fartos los leones non fazen mal a ninguno [...] (Alfonso X el Sabio, Primera parte, 2009: 551-552) ${ }^{27}$.

Texto 5

\section{CONCLUSIONES GENERALES}

Para finalizar nos gustaría puntualizar algunas cuestiones que no hemos podido determinar a lo largo de este ensayo, así como también exponer algunas reflexiones generadas tras la elaboración de éste.

En primer lugar, es nuestro deber recalcar que la inicial intención del rey Sabio era la de unificar sus dos coronas (es decir, aunar ideológicamente ambos reinos históricamente enfrentados, intentando convertirlos en uno). Motivo por el cual sus dos figuras heráldicas, tanto la del Castillo como la del León, fueron siempre de la mano, reflejándose la idea de un posible imperio hispánico y pretendiendo la soberanía sobre los demás reinos de la península bajo su doble corona, utilizando para esto la propagación de sus dos símbolos.

Por otro lado, necesitamos puntualizar la presencia y protagonismo de Plinio el Viejo y su Historia Natural en estas citas, así como también el uso de alguna versión de un Fisiólogo latino o romance ${ }^{28}$ y del libro de las Etimologías de san Isidoro de Sevilla. Pero al mismo tiempo viéndose una toma de información selectiva en beneficio del simbolismo que se quería dar de este animal en la General Estoria.

De los textos aquí expuestos hemos visto cómo a través del emblema

27. Tomando como fuente principal la Historia Natural de Plinio el Viejo (2003: 139).

28. El uso del Fisiólogo para la elaboración de esta obra es muy importante debido a que no nos han llegado manuscritos de esta época y de este espacio, demostrando el uso y conocimiento del Fisiólogo, ya fuere de manera directa o indirecta, tal y como expresaba la teoría del gran hispanista británico, el profesor A. Deyermond, según el cual la sabiduría del bestiario cristiano discurría en la España medieval a través de los sermones de los predicadores. En palabras del propio Deyermond: "Y los bestiarios fueron un recurso importante para los predicadores, sobre los que predicaron en la lengua vernácula ante un público laico" (Deyermond, 2004: 88). 
del león se describía tanto a un monarca piadoso, que exime a sus súbditos (textos 1 y 2), como a un monarca bondadoso y noble que llora al tener que dejar a sus hijos (texto 4), y en esta línea percibimos la intención de eternidad de los reyes al ensalzar las cualidades longevas del león (texto $3)$.

Por último, y no por ello menos reseñable, encontramos la descripción iconográfica que protagonizaba la impronta del león heráldico del reino, siendo esta representación muy importante ya que fue la que invadió todo un universo simbólico y visual (basado en la heráldica de los reyes de León) que a día de hoy conservamos (texto 5).

Como acabamos de ver el símbolo del león ocupa un papel trascendente dentro de esta obra, siendo el león utilizado como un reflejo del monarca, es decir, en palabras de la profesora Morales Muñiz:

La llamada imagen del espejo se utiliza para explicar la respuesta que el hombre medieval ofreció para definirse a sí mismo. Es decir, el ser humano se definía por el otro, que era el animal. Colocando al animal en situación o posición humana, precisamente porque no era humano, el hombre pudo realzar su propia humanidad o resumir todos sus fallos [...] (Morales Muñiz, 2000: 327).

\section{REFERENCIAS BIBLIOGRÁFICAS}

ALFONSO X EL SABIO. (1930). General Estoria. Primera parte, A. G. Solalinde (ed.). Madrid: Centro de Estudios Históricos.

(1957-1961). General Estoria, Segunda parte, A. G. Solalinde, L1. A. Kasten y V.R.B. Olschlager (eds.). Madrid: CSIC.

(2004). Las Siete Partidas: el Libro del Fuero de las Leyes. Introducción y edición dirigida por José Sánchez-Arcilla Bernal. Madrid: REUS.

(2009). General Estoria, Edición coordinada por Pedro SánchezPrieto Borja, 10 tomos. Madrid: Biblioteca Castro / Fundación José Antonio de Castro.

AYALA MARTÍNEZ, C. (2004-2005). "Relaciones del rey Alfonso X con 
Aragón y Navarra”. IV Semana de Estudios Alfonsíes, Alcanate IV, 101-146.

BRUNETTO LATINI (1989). Libro del tesoro de Brunetto Latini. Versión castellana de Li Livres dou Tresor. Editada y estudiada por Surgeon Baldwin. Madison: Hispanic Seminary of Medieval Studies.

CHARBONNEAU-LASSAY, L. (1997). El bestiario de Cristo. El simbolismo animal en la Antigüedad y la Edad Media, 2 vols. Trad. F. Gutiérrez, 2a . ed. Barcelona: Sophia Perennis, vol. 1.

DEYERMOND, A. D. (2004). "La tradición de los bestiarios en la antigua lírica popular hispánica”. En De la canción de amor medieval a las soleares: Profesor Manuel Alvar in memoriam (Actas del Congreso Internacional Lyra minima oral III, Sevilla, 26-28 de noviembre de 2001), Pedro M. Piñero Ramírez (ed.), 87-99. Sevilla: Fundación Machado / Universidad de Sevilla.

GANNON, A. (2002). "King of all beasts. Beast of all kings. Lions in Anglo-Saxon coinage and art". Pluskowski, Aleks (ed.). Medieval animals. Archaeological Review from Cambridge 18, 22-37.

GARCÍA GARCÍA, F. A. (2008). "El león y el trono en la iconografía medieval: imagen de poder y exégesis teológica". En CEHA. XVII Congrés Nacional d'Història de l'Art. Art i Memòria. Pre-Actes, 282-284. Barcelona: Universitat de Barcelona.

GARCÍA SOLALINDE, A. (1930). "El Physiologus en la General Estoria de Alfonso". Mélanges d histoire littéraire genérale et comparée à Fernand Baldensperger 2, 51-54.

(1934). "Fuentes de la General Estoria de Alfonso el Sabio: I. El Libro de las Provincias, o sea Isidoro, Etimologías, XIV-XV. II. Identificación de Ramiro con las Interpretaciones Nominum Hebraicorum atribuidas a Remigio de Auxerre". Revista de Filología Española XXI, 1-28.

GONZÁLEZ JIMÉNEZ, M. (2004). Alfonso X el Sabio, 1252-1284. Barcelona: Ariel.

GONZÁLEZ ROLÁN, T. (1981). "San Isidoro de Sevilla como fuente de Alfonso el Sabio: un nuevo texto de las Etimologías (L.XIV) en la General Estoria (4. " parte)". Revista de Filología Española LXI, 225-233.

GUGLIEMI, N. (2002). El Fisiólogo. Bestiario medieval. Introducción y notas de Nilda Guglielmi. Buenos Aires: Eudeba. 
GWYNN-JONES, P. (1993). Heraldic Monster. Leicester: Bison Books Ltd.

ISIDORO DE SEVILLA (2009). Etimologías. Edición bilingüe por José Oroz Reta y Manuel A. Marcos Casquero. Madrid: Biblioteca de Autores Cristianos.

KLEINE, M. (2013). "El carácter propagandístico de las obras de Alfonso X". De Medio Aevo 4, 1-42.

MALAXECHEVERRÍA, I. (2008). Bestiario medieval. Madrid: Siruela (Biblioteca medieval).

MENÉNDEZ-PIDAL DE NAVASCUÉS, F. (1982). Heráldica medieval española. 1, La casa real de León y Castilla. Madrid: Hidalguía.

(1999). Leones y castillos: emblemas heráldicos en España. Madrid: Real Academia de la Historia.

MONTELlS Y GALÁN, J. M. ${ }^{a}$ (1999). Diccionario Heráldico de Figuras Quiméricas y otros términos relacionados con la Ciencia del Blasón. Precedido de un prólogo de Luis Alberto de Cuenca y seguido de un Elogio del Dragón. Zaragoza: Institución Fernando el Católico.

MORALES MUÑIZ. D. C. (1996). "El simbolismo animal en la cultura medieval". Espacio, tiempo y forma. Serie III, Historia medieval 9, 229-255.

(2000). "La fauna exótica en la Península Ibérica: apuntes para el estudio del coleccionismo animal en el Medievo hispánico". Espacio, tiempo y forma. Serie III, Historia medieval 13, 233-270.

NOGALES RINCÓN, D. (2011). "El reino animal como gobierno utópico en la Castilla bajomedieval (siglos XIII-XV)". En Medievo utópico. Sueños, ideales y utopías en el imaginario medieval, 67-86. Madrid: Sílex.

PASTOUREAU, M. (1972). "Le Bestiaire Héraldique au Moyen Âge". Revue Française d'Héraldique et de Sigillographie 41, 3-17. (1984). "Quel est le roi des animaux ?". Actes des congrès de la Société des historiens médiévistes de l'enseignement supérieur public, vol.15, n. ${ }^{\circ}$ 1, 133-142. Publications de la Sorbonne (en línea: http://www.persee.fr/doc/shmes_1261-9078_1985_act_15_1_1442 [20/06/2017]).

PLINIO EL VIEJO (2003). Historia natural. Libros VII-XI. Traducción y notas de E. del Barrio Sanz. Madrid: Gredos. 
SALVO GARCÍA, I. (2010). Alfonso X el Sabio, General Estoria, VI partes (tomos I-X), Pedro Sánchez-Prieto (coord.), e-Spania (en línea: https://e-spania.revues.org/19844 [10/10/2016]).

SOCARRÁS CAYETANO, J. (1976). Alfonso X of Castile: A study on Imperialistic frustration. Barcelona: Hispam.

VALERO DE BERNABÉ, L. (2007). Análisis de las características generales de la heráldica gentilicia española y de las singularidades heráldicas existentes entre los diversos territorios históricos hispanos. Tesis doctoral defendida en la UCM.

Recibido el 1 de marzo de 2017.

Aceptado el 11 de abril de 2017. 
